montanen Art dort Erebia Medea erwartet hätte, die gar nicht mit aufgeführt wird; ob ein Schreibfehler im Artnamen vorliegt, hätte die Angabe der Flugzeit leicht entscheiden lassen. - In den Namen der Arten kommen nur wenige im Erratenverzeichnisse unberichtigte Druckfuhler vor z. B. Temarata S. 53, Acuminitana (so auch im Register) S. 81, Anexella S. 88. Hoffentlich wird der geschickte und fleissige Verfasser seine ausführlichen Beobachtungen in einem Nachtrage liefern.

\title{
A catalogue of British Neuroptera
}

by

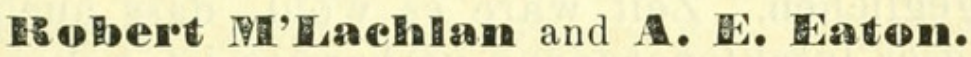

Published by the Entomological Society of London. 1870. (Price 1 shilling.)

Mit Ausnahme der professionellen Neuropterologen ist keine Klasse der Entomophilen so sehr auf das Sammeln der Neuroptera angewiesen, wie die der Schmetterlingssammler. Ilinen kommen sie bei der Schmetterlingsjagd vorzugsweise und oft zu ihrem Verdruss vor; sie sind mit den Werkzeugen, sie unversehrt zu fangen und zu transportiren, versehen; sie können sie völlig wie Schmetterlinge zubereiten und aufstellen. Nach lepidopterologischer Weise behandelt (d. h. sauber gespannt) und geordnet bieten diese Insekten einen recht wohlgefälligen Anblick und nehmen - die Libellen abgerechnet einen so geringen Raum in Anspruch, dass wenige Schubladen die vollständige Neuropternfauna einer Gegend bergen können. Wenn aber das Sammeln von Neu:optern fast inmer nur bei einem Anfunge bleibt, so trägt wohl die meiste Schuld die Schwierigkeit, sich für das Gesammelte die Namen zu verschaffen. Der Neuropter'sloge sagt zwar, das Untersuchen und Bestimmen sei leicht. Die Synonymenzahl scheint aber zu beweisen, dass selbst die Neuropterologen mit erheblichen Schwierigkeiten zu kämpfen haben. Gewiss ist, dass das Untersuchen der Gattungs- und Artenmerkmale, wie interessant es auch sein mag, für die überwiegende Mehrzahl der Lepidopteristen nicht das mindeste Anziehende besitzt. Könnten sie ihre Arten leicht benannt erhalten, so würde das ihren Sammeleifer nicht so bald erkalten lassen. So riel ich weiss, 
sind jetzt bloss zwei Autoritäten in Europa zum Bestimmen von Neuropteren bereitwillig: Dr. Brauer in Wien und Herr R. M'Lachlan in London (20, Limes Grove North, Lewisham, S. E.).

Der letztere giebt im Verein mit dem Rev. Eaton im vorliegenden Catalog die systematische Reihenfolge der 323 bisher in Britannien beobachteten Neuropteren, mit vollständiger Synonymie und Citaten, wobei mit den Pseudo-Neuropteren (den Papierläusen, bei denen noch sehr viel zu entdecken übrig ist) der Anfang, und mit den Phryganeen der Schluss gemacht wird. Die meisten Arten kommen sicher in Norddeutschland vor, und wenn die der nordenglischen und schottischen Gebirge natürlich in unseren Flächen fehlen, so wird der Mangel ohne Zweifel durch andere, worunter z. B. die in Britannien gänzlich fehlenden Ameisenlöwen gehören, völlig ausgeglichen. Zeit wäre es wohl, dass auch was bei uns aus dieser Insektenordnung vorhanden ist, bekannt würde, und da die beiden genannten Autoritäten, um das Neuropternstudium zu fördern, gern Zeit und Mühe opfern, so sollte man die gute Gelegenbeit nicht länger unbenutzt lassen. Den Lepidopteristen lässt sich mit der Zeit eine Santmlung in Aussicht stellen, an deren Vervollständigung sie ohne grosse Mühe und mit Vergnügen arbeiten, und die sie nach dem vortrefflich gedruckten Catalog schönstens ordnen können. 


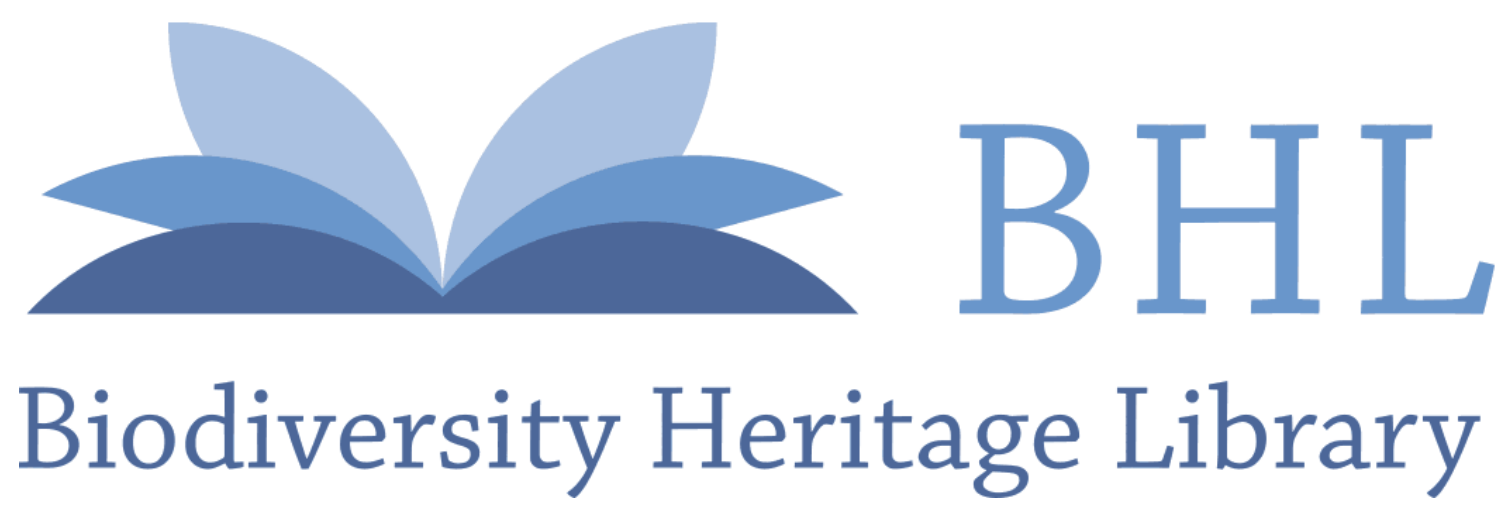

McLachlan, Robert and Eaton, A. E. 1870. "A catalogue of British Neuroptera." Entomologische Zeitung 31, 425-426.

View This Item Online: https://www.biodiversitylibrary.org/item/35851

Permalink: https://www.biodiversitylibrary.org/partpdf/205924

\section{Holding Institution}

Smithsonian Libraries

\section{Sponsored by}

Smithsonian

\section{Copyright \& Reuse}

Copyright Status: NOT_IN_COPYRIGHT

This document was created from content at the Biodiversity Heritage Library, the world's largest open access digital library for biodiversity literature and archives. Visit BHL at https://www.biodiversitylibrary.org. 